\title{
Brouhaha erupts over testosterone-testing advertising campaign
}

$\mathrm{F}$ ederal regulators are allowing a testosterone manufacturing firm to skirt direct-to-consumer advertising law, and may be risking lives, by allowing it to conduct an advertising campaign promoting testosterone testing, a group of doctors, pharmacists and researchers charge.

Abbott Canada launched the print advertising campaign - under the banner "Has He Lost That Loving Feeling?" - during the summer, urging men to get their testosterone tested if they lacked energy, had a low sex drive or had nonspecific symptoms such as falling asleep after dinner. The campaign also involved mailouts to doctors and the creation of a website about low testosterone levels (www.LowT.ca).

Abbott manufactures testosterone gel (AndroGel), the leading testosterone product in its class of sex hormones in Canada. The drug captured $73 \%$ of Canadian market share in 2010, generating about $\$ 27$ million in retail sales from pharmacies, according to IMS Brogan, a health services consulting firm.

The advertising campaign promotes off-label use of a drug and is "a classic case of disease-mongering," says Barbara Mintzes, an epidemiologist and assistant professor in anesthesiology, pharmacology and therapeutics at the University of British Columbia.

It also poses a public health concern and is likely to drive men to their family doctors for unnecessary testing for what is a normal consequence of ageing, she adds. "My concern is that ... in order to promote sales of its testosterone gel, Abbott is promoting the idea that getting older has become a disease state for men."

Mintzes adds that a study that was discontinued because of health risks indicated there are increased rates of adverse cardiovascular events in older men who are taking a testosterone replacement (N Engl J Med 2010;363;

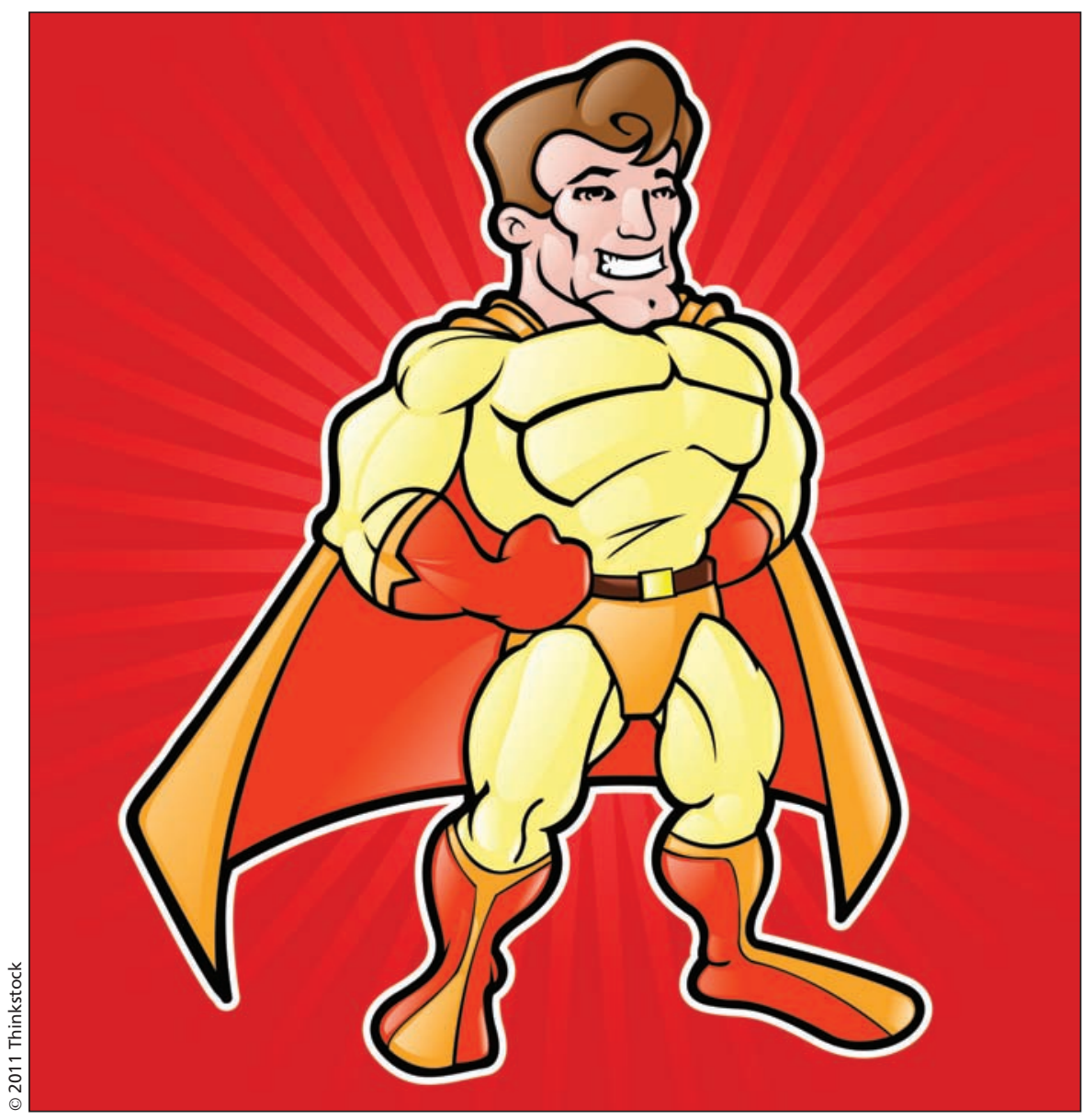

Critics charge that an advertising campaign is promoting off-label use of testosterone gels for nonmedical purposes.

109-122). "There could be a harm to public health because of (potential) cardiovascular complications and the potential for undiagnosed prostate cancer to be stimulated," she says.

Mintzes and 24 other researchers, doctors and pharmacists penned a letter to the Pharmaceutical Advertising Advisory Board complaining about the Abbott campaign and accusing the firm of contravening the Food and Drugs Act by providing "misleading and inaccurate information that would not withstand any serious test of truth in advertising, and is likely to lead to unjustified increases in health care costs."
While hypogonadism, or lack of enough testosterone, is a serious disease that warrants the use of testosterone gel, most men are not suffering from hypogonadism but rather, from declining testosterone levels, a natural condition of aging, Mintzes says.

The campaign is a disguised form of direct-to-consumer advertising of a prescription drug, which is prohibited in Canada, she says. If the effect is to stimulate sales of testosterone products in Canada, Abbott will automatically benefit because of its market share, she adds.

The Pharmaceutical Advertising Advisory Board referred the complaint to Health Canada, saying it lacked a 
process for dealing with complaints about advertising directed at consumers. By contrast, the Board has a well-defined process for complaints about advertising directed at health care professionals, such as pharmaceutical ads in medical journals.

Health Canada rejected the group's concerns, saying that such "help-seeking messages" are not considered advertisements under the Food and Drugs Act because they do not mention a specific firm or product.

Although Health Canada supports the World Health Organization's Ethical Criteria for Medicinal Drug Promotion, "it is the Department's view that this particular campaign is not promotional in nature," Robert Liteplo, acting director of Health Canada's Therapeutic Effectiveness \& Policy Bureau, wrote in a letter to Mintzes. "Therefore, the legislative and regulatory advertising provisions do not apply in the dissemination of this campaign."

In response to the concern that offlabel use of testosterone gels is being promoted, Liteplo wrote that manufacturers must provide "substantive scientific evidence" regarding the safety, efficacy and quality of a drug before Health Canada approves any prescription drug for sale in Canada.

Mintzes found it "odd" that the Pharmaceutical Advertising Advisory Board does not have the power to investigate direct-to-consumer advertising.

Testosterone gel was approved for sale in Canada as a treatment for hypogonadism. The product monogram specifically cautions against using the drug to treat "non-specific symptoms" suggestive of hypogonadism if that deficiency has not been confirmed by laboratory testing and unless other possible causes have been excluded. The monograph also warns against using the drug if prostate cancer is suspected.

Abbott Canada says that it launched the advertisements as a "direct-topatient disease awareness campaign."

"It's unbranded" and is aimed at drawing people to the website and raising awareness of low testosterone among men who may be at risk, says Eileen Murphy, manager of communications for Abbott.

Murphy was "unaware" whether the company has taken other steps to bolster sales of AndroGel in Canada, such as sending sales representatives to visit doctors and provide samples of the medication. - Laura Eggertson, Ottawa, Ont.

CMAJ 2011. DOI:10.1503/cmaj.109-4000 